es manejable y al mismo tiempo condensa entre sus páginas la información necesaria para que podamos hacernos un panorama bastante completo de los debates, enfoques y términos que el filólogo debe manejar siempre que se acerque al texto poético con intención de analizarlo y entenderlo.

Marcos García PÉrez Universidad Autónoma de Madrid

\title{
RODRIgo Olay VALDÉs, El endecasílabo blanco: la apuesta por la renovación poética de G. M. de Jovellanos, Oviedo, Instituto Feijoo de Estudios del Siglo XVIII, 2020.
}

unque sus métodos y objetivos puedan parecer muy dis-
pares, es indudable el beneficio que los estudios de Métrica y
Poética proporcionan a las investigaciones de crítica textual,
y así se comprueba en multitud de trabajos. Tal es el caso de M. de Jovellanos, de Rodrigo Olay. El autor, especialista en Feijoo y el siglo XVIII, además de reconocido poeta, ha escrito una monografía que aúna la amplitud de referencias bibliográficas con la precisión de sus planteamientos y conclusiones, y la ambición de sus objetivos con la brevedad expositiva. Gaspar Melchor de Jovellanos se nos presenta en él como el teórico fundamental del endecasílabo blanco, dentro del movimiento de superación del conceptismo barroco que tiene lugar en la poesía del siglo XVIII. Sus ideas sobre la tipología y empleo de este tipo de verso se encuentran recogidas en una serie de borradores y cartas que, entre 1773 y 1797, escribió a algunas de sus amistades. Si bien estas ideas ya habían sido objeto de estudios previos, el libro de Rodrigo Olay tiene la originalidad de presentar un análisis detallado de la frecuencia estadística con la que aparecen las distintas formas métricas, los tipos de verso y, dentro de los endecasílabos, sus distintas variedades, en la obra de Jovellanos a lo largo de sucesivos decenios. Los resultados de este recuento se recogen en exhaustivas tablas de porcentajes y sirven para extraer de ellos conclusiones más generales, según el modelo de Griswold Morley y Bruerton en su estudio sobre Lope de Vega, mencionado expresamente por Olay como ejemplo de datación y reconocimiento de autoría basado en los usos métricos de un autor. Efectivamente, estos datos se aplican a la resolución de tales problemas $y$, en concreto, le permiten fundamentar la atribución de la 
«Loa a Campomanes» al autor asturiano, así como rectificar algunas dataciones de la «Elegía a la ausencia de Marina».

La visión poética de Jovellanos se resume en el segundo capítulo del libro, «Ideas métricas de Jovellanos: teoría del endecasílabo blanco». El corpus teórico del gijonés lo forman nueve documentos, más concretamente cartas y borradores, que escribió a cuatro poetas amigos: Carlos González de Posada, Francisco de Paula Caveda Solares, Juan Meléndez Valdés y Ramón de Posada y Soto. A estos cabría añadir las «Lecciones de retórica y poética», que, a pesar de las dudas de autoría que presentan, guardan una coherente similitud con lo expuesto sobre materia de versificación en su epistolario. Rodrigo Olay organiza en forma de argumentación el contenido teórico de estos escritos, de modo que el acompañamiento de otras referencias de especialistas y estudiosos en la materia no desdibuja la particular visión poética del autor gijonés. El punto de partida de las ideas de Jovellanos sobre el verso blanco es la, por desgracia, frecuente oposición entre rima, por un lado, y libertad y precisión en la expresión poética, por otro. Olay explica cómo, con el fin de evitar el prosaísmo en que podía incurrir el uso continuado del verso blanco, Jovellanos insiste en el empleo de variados juegos rítmicos. Para ello, el vehículo más adecuado es el endecasílabo, por ser el verso simple más extenso en castellano (no se considera aquí el dodecasílabo simple), y por tanto el que permite mayor flexibilidad en la disposición de los acentos. En este punto es importante volver a subrayar su consideración como metro simple, puesto que, como veremos, Jovellanos clasifica los endecasílabos según la posición de su cesura; pero tal cesura no se confunde con la pausa del mismo nombre, idéntica a todos los efectos a la pausa versal o final de verso, y que separa los hemistiquios de los versos compuestos. Partiendo, por lo tanto, del aparente conflicto entre rima y libertad de expresión, se destacan los referentes anglosajones de Jovellanos para su teoría del verso suelto, especialmente Milton, de cuyo Paradise Lost tradujo el autor asturiano el primer canto.

Este capítulo resume también las ideas principales de Jovellanos en materia de versificación. Rodrigo Olay ordena y expone de manera sistemática los puntos dispersos en las distintas cartas del autor gijonés, para establecer que se trata de una teoría métrica centrada en el oído, en los efectos estéticos de la acústica del verso. Con este fin, Jovellanos asegura haber tomado como referencia a los poetas considerados como más armoniosos (Garcilaso y fray Luis), y como contraejemplo a los más duros (Hurtado de Mendoza y Hernández de Velasco). A partir de estas lecturas, los endecasílabos se clasifican según cinco «cesuras», 
en función de que los acentos de la cuarta sílaba recaigan sobre palabra aguda o llana, y los de la sexta en aguda, llana o esdrújula. Cabría añadir aquí que sólo esta variedad de terminaciones, que no afecta al cómputo silábico, basta para demostrar que la «cesura» de Jovellanos no constituye una auténtica pausa, en el sentido propio del término. Olay resume esta clasificación con claridad, y también sistematiza de forma breve y sencilla la jerarquía establecida por Jovellanos entre las diferentes cesuras, así como las combinaciones de ellas que resultan más aconsejables. Otros principios de su teoría poética, como evitar la repetición cacofónica de sonidos, las asonancias y rimas internas, o los finales agudos y esdrújulos, son más comunes, y pueden encontrarse en teóricos y tratadistas precedentes. No deja de resultar llamativa la honestidad de Jovellanos, quien, tal como oportunamente cita el autor del libro, reconocía haber renunciado a buena parte de las prácticas por él recomendadas, ya que le suponían demasiada dificultad unidas a su «falta de numen y de uso».

Una vez planteada su teoría, los capítulos que van del tercero al cuarto exponen los datos de porcentaje y frecuencia obtenidos del recuento estadístico, con las conclusiones que pueden extraerse de ellos. En «Usos métricos de Jovellanos: descripción», se aprecia cómo el catálogo de formas poéticas empleado por el autor gijonense no es muy extenso ni especialmente novedoso, aunque sí destaca su progresiva decantación por el endecasílabo blanco. Esta tendencia se ve ampliamente expuesta en el siguiente capítulo, «Usos métricos de Jovellanos: evolución», donde se aprecia claramente el abandono del género anacreóntico que lleva a cabo Jovellanos en el último cuarto del siglo XVIII, a medida que va encontrando su propio estilo y sus lecturas se internacionalizan. En «Uso del endecasílabo blanco: estudio cuantitativo» se muestra, en cambio, la evolución del poeta en el manejo de su verso preferido durante estas décadas, desde el predominio de los endecasílabos con cesura en $7^{\mathrm{a}}$ sílaba, considerada por él como la menos armoniosa, hasta su progresiva reducción en favor de los que la tienen en $4^{\mathrm{a}}, 5^{\mathrm{a}}$ y $6^{\mathrm{a}}$ sílaba, clasificados como los más agradables. También se proporcionan en este capítulo los datos que relacionan la rima con las variedades endecasilábicas. Así, la asonancia es más frecuente en aquellos con cesura en $4^{\mathrm{a}}$ y $6^{\mathrm{a}}$ sílaba, aunque esto pudiera deberse más bien, según Rodrigo Olay, a su inclusión en textos dramáticos, por la eufonía inherente a estos tipos de endecasílabo. En cambio, el uso de rima consonante parece estar en correlación con las variedades que tienen cesura en $5^{\mathrm{a}}$ y $7^{\mathrm{a}}$ sílaba. Por último, el capítulo «Uso del endecasílabo blanco: estudio cualitativo» revela cómo Jovellanos 
hace una aplicación desigual de sus propios criterios estéticos: si bien logra evitar los adjetivos en final de verso, así como las terminaciones agudas o esdrújulas, y el uso de palabras muy largas, no consiguió eliminar ni reducir las recurrencias fónicas, las rimas internas o asonancias ocasionales en sus versos, como tampoco las sinalefas duras.

En las «Reflexiones finales» traza Olay una panorámica del verso blanco en la tradición europea, con la finalidad de señalar el papel que le atribuye a Jovellanos en el cultivo de esta forma en lengua española. Este recorrido comienza por los ejemplos clásicos del endecasílabo en Garcilaso y Boscán, y por el blank verse de Milton y Dryden, para centrarse en el neoclasicismo como impulsor de la ruptura con el conceptismo barroco. Dentro de este movimiento de renovación se ubica Jovellanos como teórico y reivindicador del verso suelto, que encontrará cultivadores en el Unamuno de El Cristo de Velázquez, el Juan Ramón Jiménez de madurez, y varios poetas de la generación del 27, sobre todo Cernuda. Posteriormente, Olay menciona las afinidades formales con la generación del 36, de modo particular en los ejemplos de «poesía social». Respecto a usos métricos más concretos, como el endecasílabo, se citan Vicente Aleixandre, nuevamente Cernuda, Ángel González, Claudio Rodríguez, Francisco Brines, Luis Alberto de Cuenca, Jon Juaristi o Julio Martínez Mesanza. También la silva libre de ritmo endecasilábico, con una atención especial a la variedad prosódica que trata de evitar la repetición de ritmos, se convierte en una forma frecuente a partir de la poesía del 50, como se aprecia en el ejemplo de Gil de Biedma, continúa en los años 70, con Guillermo Carnero, y sigue hasta la actualidad. 